\title{
Author Correction: Energy investment needs for fulfilling the Paris Agreement and achieving the Sustainable Development Goals
}

David L. McCollum (D), Wenji Zhou, Christoph Bertram, Harmen-Sytze de Boer, Valentina Bosetti, Sebastian Busch, Jacques Després, Laurent Drouet (D), Johannes Emmerling (D), Marianne Fay, Oliver Fricko, Shinichiro Fujimori (D), Matthew Gidden, Mathijs Harmsen, Daniel Huppmann (D), Gokul lyer (D), Volker Krey, Elmar Kriegler, Claire Nicolas, Shonali Pachauri, Simon Parkinson, Miguel Poblete-Cazenave, Peter Rafaj, Narasimha Rao (D), Julie Rozenberg, Andreas Schmitz, Wolfgang Schoepp, Detlef van Vuuren (D) and Keywan Riahi

Correction to: Nature Energy https://doi.org/10.1038/s41560-018-0179-z, published online 18 June 2018.

In the version of 'Supplementary Data 1' originally published with this Article, the units for the 'Capacity|Electricity ${ }^{\star \text { ’ }}$ variables in the 'Non_Investment_Annual' tab were incorrectly given as EJ/yr; they should have read GW. This has now been corrected. Also, some of the variables listed in the 'Non_Investment_Variable_Defs' were not required and have therefore been removed. 